\title{
Methionine deficiency does not increase polyamine turnover through depletion of hepatic $S$-adenosylmethionine in juvenile Atlantic salmon
}

\author{
Marit Espe ${ }^{1 *}$, Synne Marte Andersen ${ }^{1}$, Elisabeth Holen ${ }^{1}$, Ivar Rønnestad $^{2}$, Eva Veiseth-Kent ${ }^{3}$, \\ Jens-Erik Zerrahn ${ }^{4}$ and Anders Aksnes ${ }^{5}$ \\ ${ }^{1}$ National Institute of Nutrition and Seafood Research (NIFES), PO Box 2029, N-5817 Bergen, Norway \\ ${ }^{2}$ Department of Biology, University of Bergen, PO Box 7803, N-5020 Bergen, Norway \\ ${ }^{3}$ Nofima, PO Box 210, N-1431Ås, Norway \\ ${ }^{4}$ Evonik Degussa International AG, Havneparken 2, Vejle DK-7100, Denmark \\ ${ }^{5}$ Ewos Innovation AS, N-4335 Dirdal, Norway
}

(Submitted 11 February 2014 - Final revision received 25 May 2014 - Accepted 23 June 2014 - First published online 8 September 2014)

\begin{abstract}
During the last few decades, plant protein ingredients such as soya proteins have replaced fishmeal in the diets of aquacultured species. This may affect the requirement and metabolism of methionine as soya contains less methionine compared with fishmeal. To assess whether methionine limitation affects decarboxylated $S$-adenosylmethionine availability and polyamine status, in the present study, juvenile Atlantic salmon were fed a methionine-deficient plant protein-based diet or the same diet supplemented with DL-methionine for 8 weeks. The test diets were compared with a fishmeal-based control diet to assess their effects on the growth performance of fish. Methionine limitation reduced growth and protein accretion, but when fish were fed the DL-methionine-supplemented diet their growth and protein accretion equalled those of fish fed the fishmeal-based control diet. Methionine limitation reduced free methionine concentrations in the plasma and muscle, while those in the liver were not affected. $S$-adenosylmethionine (SAM) concentrations were higher in the liver of fish fed the methionine-deficient diet, while $S$-adenosylhomocysteine concentrations were not affected. Putrescine concentrations were higher and spermine concentrations were lower in the liver of fish fed the methionine-deficient diet, while the gene expression of SAM decarboxylase $(S A M d c)$ and the rate-limiting enzyme of polyamine synthesis ornithine decarboxylase (ODC) was not affected. Polyamine turnover, as assessed by spermine/spermidine acetyltransferase (SSAT) abundance, activity and gene expression, was not affected by treatment. However, the gene expression of the cytokine $T N F-\alpha$ increased in fish fed the methionine-deficient diet, indicative of stressful conditions in the liver. Even though taurine concentrations in the liver were not affected by treatment, methionine and taurine concentrations in muscle decreased due to methionine deficiency. Concomitantly, liver phospholipid and cholesterol concentrations were reduced, while NEFA concentrations were elevated. In conclusion, methionine deficiency did not increase polyamine turnover through depletion of hepatic SAM, as assessed by SSAT activity and abundance.
\end{abstract}

Key words: Methionine: Trans-sulphuration: Taurine: $S$-Adenosylmethionine decarboxylase: Polyamine turnover: Spermine/ spermidine acetyltransferase: Atlantic salmon

During the last few decades, plant ingredients have replaced fishmeal in the diets of aquacultured species. Plant ingredients such as soya proteins contain low concentrations of the indispensable amino acid methionine, even though the concentrations of the total sulphur amino acids are relatively high. Furthermore, none of the plant protein ingredients contain taurine and most are low in choline. Previously, we had reported that Atlantic salmon synthesised taurine resulting in a relatively stable hepatic taurine:free methionine ratio at adequate methionine intake levels ${ }^{(1)}$. Methionine deficiency has been found to increase hepatic
TAG concentrations in Atlantic salmon and concomitantly reduce hepatic taurine and bile acid concentrations ${ }^{(2)}$. In the study of Espe et $a l^{(2)}$, the high-plant protein diets were not supplemented with either choline or taurine. Thus, we could not distinguish whether the increased hepatic TAG concentrations were due to a methionine-choline deficiency or to a deficiency of either of them. Methionine is an important methyl donor in all animals, including fish, and the higher the methionine intake, the higher the hepatic $S$-adenosylmethionine (SAM) concentration ${ }^{(1)}$. Trans-sulphuration results in the formation of cystathionine by the rate-limiting enzyme

Abbreviations: BHMT, betaine-homocysteine methyltransferase; CBS, cystathionine- $\beta$-synthase; PC, phosphatidylcholine; PEMT, phosphatidylethanolamine methyltransferase; PL, phospholipids; SAH, S-adenosylhomocysteine; SAM, S-adenosylmethionine; SSAT, spermine/spermidine acetyltransferase. 
cystathionine- $\beta$-synthase (CBS), and cysteine produced from cystathionine can either be incorporated in glutathione or be metabolised to taurine ${ }^{(3,4)}$. Glutathione and taurine as well as methionine itself are known to function as antioxidants in tissues. Therefore, limitation of methionine or its metabolites may affect the oxidative status in animals, resulting in inflammation and apoptosis ${ }^{(5-8)}$.

In addition to acting as a methyl donor, SAM can function as an aminopropyl donor in polyamine synthesis when decarboxylated by the enzyme SAM decarboxylase (SAMdc) ${ }^{(3,9-11)}$. Polyamine catabolism and turnover require the enzyme spermine/spermidine acetyltransferase $\left(\right.$ SSAT) ${ }^{(11,12)}$. Previously, we had found that juvenile salmon fed diets low in taurine in addition to containing more lipids ${ }^{(13)}$ had higher hepatic polyamine concentrations. Atlantic salmon fed plant proteinbased diets with fish protein concentrate, increasing dietary taurine content, had low viscera mass relative to body weight and a higher hepatic free arginine:lysine ratio even though the content of these amino acids was similar in the diets and there were no differences in voluntary feed intake ${ }^{(14)}$. Concomitantly, hepatic spermine concentrations were increased in fish fed diets containing fish protein concentrate when compared with those in fish fed diets without fish protein concentrate. This indicates that the availability of methionine and/or its metabolites for methylation reactions may affect the viscera mass and this seems to affect trans-sulphuration and polyamine turnover by reducing the amount of hepatic SAM to be decarboxylated and used in polyamine synthesis, which may increase polyamine turnover. Any increase in polyamine turnover may deplete ATP and acetyl-CoA in cells, thereby interfering with lipid metabolism through an increased activity of mitochondrial $\beta$-oxidation ${ }^{(10-12,15)}$. In addition, elevated degradation of polyamines may contribute to an increased production of reactive oxygen species through an increased activity of polyamine oxidases ${ }^{(11)}$.

Thus, we postulated that methionine limitation reduces methylation capacity by reducing the SAM:S-adenosylhomocysteine (SAH) ratio and the anti-oxidative status through reduced trans-sulphuration and that SAM depletion reduces the amount of SAM being decarboxylated and used for polyamine synthesis. Because of reduced polyamine synthesis, an increased turnover of polyamines through SSAT, consuming ATP and acetyl-CoA, might occur. Then, any reduced acetylCoA remaining in cells activates carnitine palmitoyltransferase 1 (CPT-1), the rate-limiting enzyme of long-chain fatty acid oxidation, leading to reduced lipid depots. To test this hypothesis, juvenile Atlantic salmon were fed plant protein-based diets supplemented or not supplemented with crystalline DL-methionine by keeping the concentrations of taurine and cysteine as well as of other indispensable and dispensable amino acids equal to and above the established requirement $^{(16)}$ and comparable to the fishmeal amino acid profile. To prevent methionine-choline deficiency, choline was added to both the DL-methionine-supplemented and methionine-deficient diets to match the traditional fishmeal-based diets. To determine whether these diets supported optimum growth performance and thus normal metabolism, a group was fed a positive control diet containing fishmeal as the protein source and compared with the other two groups.

\section{Materials and methods}

\section{Diets}

The test diets contained plant protein either supplemented or not supplemented with DL-methionine $0.45 \%$. The methionine added was exchanged with tapioca on a weight basis so as not to alter the protein content of the experimental diets. Furthermore, crystalline threonine and lysine were added to these diets to balance the concentrations of all the indispensable amino acids to values similar to those of the fishmeal-based control diet. In addition, $0 \cdot 3 \%$ taurine was added to the diets to mimic the taurine content in the fishmeal-based control diet. Fish oil was used as the lipid source. The diets were extruded and the pellet size was $1.5 \mathrm{~mm}$. The composition of the diets and the amino acid profiles of these diets are given in Tables 1 and 2, respectively. A control diet with fishmeal as the protein source was also used for comparison of growth performance.

\section{Fish experiment}

The feeding experiment was conducted from May to July 2011 using $11 \mathrm{~g}$ Atlantic salmon (Salmo salar) grown in fresh water. A total of 100 fish were hand-sorted and arbitrarily distributed into each of the twelve glass fibre tanks $(0.6 \mathrm{~m} \times 0.6 \mathrm{~m})$ filled with 165 litres of water. Fish were acclimatised in the experimental tanks for 3 weeks with a commercial diet. A total of four replicate tanks were used for each of the experimental diets. Fish were bulk-weighed before the experiment and every 2nd week after the start of experimental diet feeding and after 8 weeks of feeding. Fish were fed ad libitum the first 2 weeks and then fed at $95 \%$ of the expected requirement derived from tabulated values. A continuous light regimen was chosen, and fish were pulse-fed using automatic feeders

Table 1. Composition $(\mathrm{g} / \mathrm{kg})$ of the experimental diets

\begin{tabular}{lccc}
\hline & $\begin{array}{c}\text { Met } \\
\text { deficient }\end{array}$ & $\begin{array}{c}\text { Met } \\
\text { supplemented }\end{array}$ & $\begin{array}{c}\text { Positive } \\
\text { control }\end{array}$ \\
\hline Fishmeal & 150 & 150 & 760 \\
Plant protein blend* & 528 & 528 & 0 \\
Premix & $57 \cdot 3$ & $57 \cdot 3$ & $14 \cdot 3$ \\
DL-Met† & 0 & $4 \cdot 5$ & 0 \\
Amino acid mix $¥$ (\% of the mix) & $8 \cdot 3$ & $8 \cdot 3$ & 0 \\
Fish oil & $156 \cdot 7$ & $156 \cdot 7$ & $125 \cdot 7$ \\
Choline chloride & $4 \cdot 0$ & $4 \cdot 0$ & 0 \\
Tapioca & $95 \cdot 7$ & $91 \cdot 2$ & 100 \\
DM & 970 & 950 & 940 \\
Protein & 537 & 531 & 548 \\
Lipid & 173 & 164 & 208 \\
Ash & 80 & 79 & 91 \\
Energy (MJ/kg) & 21.7 & 21.5 & $22 \cdot 3$ \\
\hline
\end{tabular}

* Plant protein blend contained pea and soya protein concentrates $(1: 0.76, w / w)$. The premix contained minerals and vitamins fulfilling the requirement of Atlantic salmon. †Crystalline DL-methionine was exchanged with tapioca so as not to alter the protein ingredients in the plant-based diets.

¥Threonine: $51 \cdot 8$; lysine: $12 \cdot 1$; and taurine: $36 \cdot 1$. 
Table 2. Amino acid (AA) composition ( $g / 100 \mathrm{~g}$ diet $(\mathrm{g} / 16 \mathrm{~g} \mathrm{~N}))$ of the experimental diets

\begin{tabular}{|c|c|c|c|c|c|c|}
\hline & \multicolumn{2}{|c|}{ Met deficient } & \multicolumn{2}{|c|}{ Met supplemented } & \multicolumn{2}{|c|}{ Positive control } \\
\hline & $\mathrm{g} / 100 \mathrm{~g}$ & $\mathrm{~g} / 16 \mathrm{~g} \mathrm{~N}$ & $\mathrm{~g} / 100 \mathrm{~g}$ & $\mathrm{~g} / 16 \mathrm{~g} \mathrm{~N}$ & $\mathrm{~g} / 100 \mathrm{~g}$ & $g / 16 \mathrm{~g} \mathrm{~N}$ \\
\hline Asp & $5 \cdot 62$ & $10 \cdot 46$ & 5.41 & $10 \cdot 19$ & 4.65 & 8.48 \\
\hline Glu & $8 \cdot 13$ & $15 \cdot 14$ & $7 \cdot 79$ & 14.67 & $6 \cdot 74$ & $12 \cdot 30$ \\
\hline $\mathrm{OH}$-pro & \multicolumn{2}{|c|}{ ND } & \multicolumn{2}{|c|}{ ND } & 0.31 & 0.57 \\
\hline Ser & 2.41 & 4.49 & $2 \cdot 37$ & 4.46 & $2 \cdot 10$ & 3.83 \\
\hline Gly & $2 \cdot 10$ & 3.91 & 2.01 & 3.79 & $2 \cdot 68$ & 4.89 \\
\hline His & $1 \cdot 13$ & $2 \cdot 10$ & $1 \cdot 11$ & 2.09 & 1.07 & 1.95 \\
\hline Arg & 3.41 & 6.35 & 3.35 & $6 \cdot 31$ & $2 \cdot 74$ & $5 \cdot 00$ \\
\hline Thr & 2.36 & 4.39 & $2 \cdot 26$ & $4 \cdot 14$ & $2 \cdot 12$ & 3.88 \\
\hline Ala & 2.40 & 4.47 & 2.25 & 4.24 & 3.08 & $5 \cdot 62$ \\
\hline Pro & $2 \cdot 12$ & 3.95 & $2 \cdot 13$ & 4.01 & 1.89 & 3.45 \\
\hline Tyr & 1.67 & $3 \cdot 11$ & 1.60 & 3.01 & 1.50 & 2.74 \\
\hline Val & 2.45 & 4.56 & $2 \cdot 34$ & 4.41 & 2.56 & 4.67 \\
\hline Met & 0.79 & 1.47 & $1 \cdot 14$ & $2 \cdot 15$ & 1.43 & $2 \cdot 61$ \\
\hline Cys & 0.57 & 1.06 & 0.57 & 1.07 & 0.51 & 0.93 \\
\hline Ile & $2 \cdot 23$ & $4 \cdot 15$ & $2 \cdot 14$ & 4.03 & 2.09 & $3 \cdot 81$ \\
\hline Leu & 3.93 & 7.32 & 3.80 & $7 \cdot 16$ & 3.76 & $6 \cdot 86$ \\
\hline Phe & 2.44 & 4.54 & 2.44 & 4.60 & 1.98 & $3 \cdot 61$ \\
\hline Lys & 3.68 & 6.85 & 3.43 & 6.46 & 3.77 & $6 \cdot 88$ \\
\hline Trp & 0.51 & 0.95 & 0.51 & 0.96 & 0.57 & 1.04 \\
\hline$\Sigma A A$ & $47 \cdot 77$ & 88.96 & 46.45 & 87.48 & $45 \cdot 51$ & 83.05 \\
\hline IAA/DAA & \multicolumn{2}{|c|}{0.92} & \multicolumn{2}{|c|}{0.93} & \multicolumn{2}{|c|}{0.94} \\
\hline Taurine* & 0.40 & 0.75 & 0.37 & 0.70 & 0.47 & 0.86 \\
\hline Non-AA-N† & & 11.04 & & 12.52 & & $16 \cdot 95$ \\
\hline TSAA $\ddagger$ & 1.36 & 2.53 & $1 \cdot 71$ & 3.22 & 1.94 & 3.54 \\
\hline
\end{tabular}

ND, not detected; IAA, indispensable amino acids; DAA, dispensable amino acids; TSAA, total sulphur amino acids.

* Taurine is not included in the sum of $A A$.

† Non-AA-N is $\mathrm{N}$ not accounted for in the amino acid analyses.

¥TSAA is methionine + cysteine.

throughout the day and night (repeatedly fed for $0.33 \mathrm{~min}$ and then held for $7 \cdot 25 \mathrm{~min}$ ). The mean water temperature throughout the experiment was $12 \cdot 7 \pm 1 \cdot 0^{\circ} \mathrm{C}$.

For chemical analyses of whole-body composition, twenty fish were sampled at the start of the experiment and twenty fish were collected from each tank at the end of the experiment. For the calculation of hepatosomatic and viscerosomatic indices, twenty fish per tank were weighed at the end of the experiment, and their liver and gastrointestinal tissues were dissected and weighed and used. In addition, ten fish from each tank were collected and pooled samples of their liver, muscle and white adipose tissue were collected and used for chemical analyses. Blood was collected from the caudal vein of ten fish in each tank into heparinised syringes and centrifuged at $1800 \mathrm{~g}$ for $10 \mathrm{~min}$ to obtain pooled plasma. For enzyme activity, protein abundance and gene expression analyses, three fish from each tank were dissected and individual liver and white adipose tissue samples were flash frozen in liquid $\mathrm{N}_{2}$. The remaining fish in each experimental tank were weighed and used for the calculation of growth performance. All fish collected were fed until sampling.

The experimental protocol was approved by the Norwegian Board of Experiments with Living Animal.

\section{Chemical analyses}

Dietary crude composition of DM, protein, lipids, ash and energy was analysed as described by Espe et al. ${ }^{(17)}$. Dietary amino acid composition was determined after hydrolysis for $22 \mathrm{~h}$ at $110^{\circ} \mathrm{C}$ in $6 \mathrm{M}-\mathrm{HCl}$ containing $3.125 \mathrm{~mm}$-Norvaline (internal standard) and $3 \mathrm{~mm}$-dithiothreitol (to protect the sulphur amino acids against oxidation) and pre-column derivatised with $\mathrm{AccQTag}^{\mathrm{TM}}$ at $55^{\circ} \mathrm{C}$ as described by Waters. The amino acids were separated on a ultra-performance liquid chromatography (UPLC) system (Waters Acquity UPLC BEH $\mathrm{C}_{18}$ column with an internal diameter of $1.7 \mu \mathrm{M}$ at a flow rate of $0.7 \mathrm{ml} / \mathrm{min}$ using the gradient provided by the supplier). The concentrations of amino acids were calculated using external standards supplied by Sigma. The concentrations of amino acids in deproteinised plasma, liver and muscle samples were determined on the Biochrom 20 Plus Amino Acid Analyzer (Amersham Pharmacia Biotech) equipped with a Li column using post-column derivatisation with ninhydrin as described by Espe et $a l^{(17)}$. The concentrations of SAM and SAH were determined on a reversed-phase HPLC system after deproteinisation in $0.4 \mathrm{M}-$ $\mathrm{HClO}_{4}$ as described by Wang et al. ${ }^{(18)}$. SAM and SAH were quantified using standards of the respective metabolites (Sigma). The plasma concentrations of total cholesterol, total phospholipids (PL), TAG and total bile acids were determined using commercial kits (Diagnostic Laboratories) according to the supplier's instructions. The lipid classes (TAG, phosphatidyl ethanolamine, phosphatidylcholine (PC), PL, NEFA and total cholesterol) in the liver were analysed using the high-performance thin layer chromatography method after extraction of lipids with chloroform-methanol $(2: 1, \mathrm{v} / \mathrm{v})$ as described by Bell et $a l .{ }^{(19)}$ with modifications described by Liaset et $a l .{ }^{(20)}$. The diamine putrescine and the polyamines spermine and spermidine were analysed after extraction in $0.4 \mathrm{M}-\mathrm{HClO}_{4}$ and 
pre-column derivatised with dansyl chloride as described by Liaset \& Espe ${ }^{(21)}$ and quantified using standards obtained from Sigma.

The hepatic concentrations of total glutathione were determined using a commercial kit according to the supplier's instructions (BioVision).

Soluble proteins and metabolites in the liver were extracted in four volumes of $10 \mathrm{~mm}$-Tris buffer ( $\mathrm{pH}$ 7.6) containing $1 \mathrm{~mm}$ EDTA and $0 \cdot 25 \mathrm{~m}$-sucrose. Samples were homogenised on ice and spun for $30 \mathrm{~min}$ at $8000 \mathrm{~g}$ at $4^{\circ} \mathrm{C}$ to collect supernatants. The supernatants were aliquoted and stored at $-80^{\circ} \mathrm{C}$ until analysed for protein abundance. To assess changes in the abundances of proteins involved in trans-sulphuration and transmethylation as a result of methionine deficiency, the protein abundances of CBS, betaine-homocysteine methyltransferase (BHMT), phosphatidylethanolamine methyltransferase (PEMT) and SSAT were analysed after SDS gel separation ( $12 \%$ gel), Western blotting on a polyvinylidene difluoride membrane and detection by Chemiluminescence Image Capture (Syngene) as described by Espe \& Holen ${ }^{(8)}$ using the following polyclonal primary antibodies: CBS (Abcam: ab96252); BHMT (Abcam: ab96415); SSAT (Abcam: anti-SAT1, ab54047); PEMT (Sigma: AV43558). The abundances of proteins were calculated relative to $\beta$-actin (BioNordica: 4967). The activity of hepatic SSAT was determined as described by Lin et al. ${ }^{(22)}$.

Extraction of mRNA from liver samples was performed using the EZ1 BioRobot and the RNA Universal Tissue Kit (Qiagen) according to the manufacturer's instructions. Extraction of RNA from white adipose tissue was carried out manually using TRIzol. The quality and quantity of RNA were assessed using NanoDrop ND-1000 UV and Agilent 2100 Bioanalyzer (Agilent Technologies), and the integrity of RNA was assessed using the RNA 6000 Nano LabChip ${ }^{\circledR}$ Kit (Agilent Technologies). A two-step real-time PCR analysis was conducted as described by Torstensen et $a l{ }^{(23)}$. The PCR primer sequences used were delivered by Invitrogen using the primers as described previously (ornithine decarboxylase (ODC), SAMdc, SSAT, $\beta$-actin, elongation factor-1 $\alpha$ (EF1 $\alpha$ ) ${ }^{(24)}, C P T-1^{(25)}, A p o B 100^{(23)}, T N F-\alpha^{(26)}$, cytochrome P450, family 7 , subfamily A, polypeptide $1(C y p 7 A 1)^{(27)}$, catalase (Cat) and glutathione peroxidase-3 $\left.(G P X 3)^{(28)}\right)$. $\beta$-Actin and $E F 1 \alpha$ were used as the reference genes. Normalised gene expression was calculated using the two reference genes as described and verified by Olsvik et $a l .{ }^{(29)}$ and reported as relative tank mean normalised expression after the number of fish fed the methionine-supplemented diet was set to 100 .

\section{Statistical analyses}

Values are given as tank means with their standard errors $(n 4)$. Differences in the growth and organ indices of the dietary treatment groups were evaluated by ANOVA. Differences between the dietary treatment groups were assessed using Tukey's post hoc test. All data were tested for homogeneity in variance using Levene's test. The normalised gene expression data as affected by methionine limitation was analysed for treatment differences using ANOVA after fish fed the diet supplemented with DL-methionine was set equal to 100 and the fish fed the deficient diet calculated relative to this. All statistical analyses were carried out using the STATISTICA program (version 9; StatSoft Inc.) and considered to be significantly different when $P<0 \cdot 05$.

\section{Results}

\section{Growth performance}

The growth performance of fish fed the methionine-deficient diet was significantly lower $(P=0.002)$ than that of fish fed the methionine-supplemented and fishmeal-based control diets (Table 3). Fish fed the methionine-deficient diet also had relatively higher liver weight $(P=0.009)$, reduced protein accretion $(P=0.0001)$ and less whole-body protein $(P=0.0002)$ when compared with fish fed the methioninesupplemented and fishmeal-based control diets (Table 3). As the methionine-supplemented diet supported growth equally as well as the fishmeal-based control diet, the two test diets were found to be appropriate to determine metabolic changes due to methionine deficiency in juvenile Atlantic salmon.

\section{Free amino acids in the plasma, liver and muscle}

Methionine limitation reduced free methionine concentrations in the plasma $(P=0.001)$ and muscle $(P<0.001)$, while those in the liver $(P=0 \cdot 10)$ were not affected by treatment (Fig. 1). Methionine limitation increased free lysine concentrations

Table 3. Growth performance of fish fed the experimental diets*

\begin{tabular}{|c|c|c|c|c|}
\hline & Met deficient & Met supplemented & Positive control & Pooled SEM \\
\hline Initial body weight (g) & $11 \cdot 7$ & 11.5 & $11 \cdot 8$ & 0.1 \\
\hline Final body weight $(\mathrm{g})$ & $46 \cdot 4^{\mathrm{b}}$ & $50 \cdot 4^{a}$ & $53 \cdot 0^{\mathrm{a}}$ & 0.9 \\
\hline Weight gain $(\mathrm{g})$ & $34 \cdot 7^{\mathrm{b}}$ & $38 \cdot 9^{a}$ & $41 \cdot 3^{\mathrm{a}}$ & 0.9 \\
\hline Hepatosomatic index & $1 \cdot 37^{\mathrm{a}}$ & $1 \cdot 22^{b}$ & $1 \cdot 16^{\mathrm{b}}$ & 0.4 \\
\hline Viscerosomatic index & $7 \cdot 35$ & $6 \cdot 85$ & $7 \cdot 21$ & 0.3 \\
\hline Protein gain (g/fish) & $5 \cdot 8^{b}$ & $7 \cdot 2^{\mathrm{a}}$ & $7 \cdot 4^{\mathrm{a}}$ & $0 \cdot 1$ \\
\hline Lipid gain (g/fish) & $4 \cdot 5$ & $4 \cdot 6$ & $5 \cdot 2$ & 0.2 \\
\hline Final whole-body protein $(\mathrm{g} / 100 \mathrm{~g})$ & $16 \cdot 6^{\mathrm{b}}$ & $18 \cdot 0^{\mathrm{a}}$ & $17 \cdot 6^{\mathrm{a}}$ & 0.1 \\
\hline Final whole-body lipid $(\mathrm{g} / 100 \mathrm{~g})$ & 11.9 & $11 \cdot 3$ & $11 \cdot 8$ & 0.2 \\
\hline
\end{tabular}

a,b Mean values with unlike superscript letters were significantly different $(P<0.05$; ANOVA and Tukey's post hoc test).

* When the test diets were supplemented with adequate methionine amounts, growth performance did not differ from that of fish fed the fishmeal-based control diet $(n 4)$. 

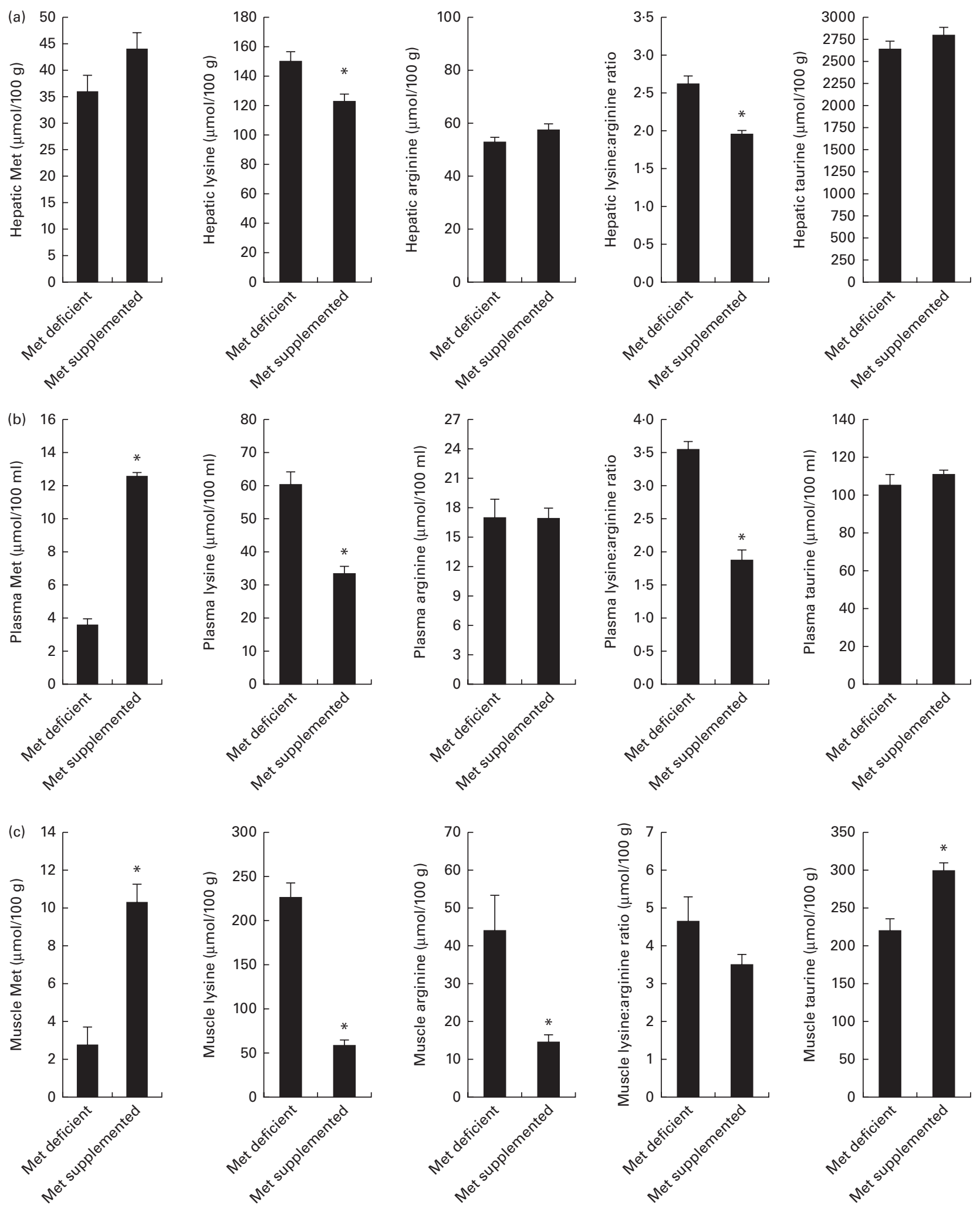

Fig. 1. Concentrations of free methionine (Met), lysine, arginine, free lysine:arginine ratio and taurine in the liver (a), plasma (b) and white trunk muscle (c) of fish fed the Met-deficient diet compared with the corresponding values in fish fed the Met-supplemented diet. All values are given in $\mu \mathrm{mol} / 100 \mathrm{~g}$ tissue or $\mu \mathrm{mol} / 100 \mathrm{ml}$ plasma. Values are means $(n 4)$, with standard errors represented by vertical bars. * Mean value was significantly different from that of fish fed the Met-deficient diet $(P<0.05)$. 
in the liver $(P=0.018)$, muscle $(P<0.001)$ and plasma $(P<0.001)$. Free arginine concentrations were elevated in the white trunk muscle $(P=0 \cdot 020)$, but not in the liver $(P=0.098)$ or plasma $(P=0.95)$, of fish fed the methioninedeficient diet, leading to a higher lysine:arginine ratio in the liver $(P=0.001)$ and plasma $(P=0 \cdot 015)$, without affecting the ratio in white trunk muscle $(P=0 \cdot 15)$ (Fig. 1). Taurine concentrations were low in the white trunk muscle $(P=0.005)$ of fish fed the methionine-deficient diet, while those in the liver $(P=0 \cdot 24)$ and plasma $(P=0 \cdot 45)$ were not affected by treatment (Fig. 1).

\section{Sulphur metabolites in the liver}

SAM concentrations $(P=0.015)$ were higher in the liver of fish fed the methionine-deficient diet, while SAH concentrations $(P=0.31)$ in the liver were not affected by treatment, resulting in an elevated capacity of methylation (i.e. the SAM:SAH ratio; $P=0.005$ ) in fish fed the methionine-deficient diet (Fig. 2).

The protein abundances of BHMT and CBS were not affected by treatment (data not shown). The concentrations of cystathionine $(P=0.008)$, the product of CBS, were reduced in fish fed the methionine-deficient diet (Fig. 2). No differences were observed in total glutathione concentrations (data not shown).

\section{Polyamines in the liver and white trunk muscle}

Putrescine concentrations $(P=0 \cdot 01)$ were elevated and spermine concentrations $(P<0 \cdot 001)$ were reduced in the liver of fish fed the methionine-deficient diet, while spermidine concentrations ( $P=0 \cdot 30)$ were not affected by treatment (Fig. 3(a)). The spermidine:spermine ratio $(P=0 \cdot 001)$ in the liver was thus higher in fish fed the methionine-deficient diet. The protein abundance of SSAT $(P=0 \cdot 20)$ in the liver was not affected by methionine limitation (Fig. 3(a)). The activity of SSAT $(P=0 \cdot 12)$ ranged from 0.37 to $0.41 \mathrm{nmol} / \mathrm{min}$ per $\mathrm{g}$ liver tissue and was not affected by methionine limitation. Neither ornithine concentrations $(P=0.55)$ nor citrulline concentrations $(P=1 \cdot 0)$ in the liver were affected by treatment (Fig. 3(a)). Both ornithine concentrations $(P=0.048)$ and citrulline concentrations $(P=0.027)$ were higher in the white trunk muscle of fish fed the methionine-deficient diet (Fig. 3(b)). Spermine concentrations $(P=0.021)$ and spermidine concentrations $(P=0.001)$ were also higher in the white trunk muscle of fish fed the methionine-deficient diet (Fig. 3(b)), while the spermidine:spermine ratio $(P=0 \cdot 45)$ remained unaffected. Putrescine concentrations $(P=0 \cdot 60)$ in white trunk muscle were not affected by methionine limitation.

\section{Lipids in the liver and plasma}

Total PL concentrations $(P=0 \cdot 001)$, and especially PC concentrations $(P=0 \cdot 01)$, were reduced in the liver of fish fed the methionine-deficient diet when compared with those in the liver of fish fed the methionine-supplemented diet (Fig. 4(a)). De novo synthesis of PC seemed to be not affected, as neither the protein abundance of phosphatidylethanolamine $(P=0 \cdot 16)$ (Fig. 4(a)) nor that of PEMT was affected by treatment (data not shown). TAG concentrations $(P=0.76)$ in the liver were not affected by treatment (Fig. 4(a)), but total cholesterol concentrations $(P=0 \cdot 01)$ and NEFA concentrations $(P=0 \cdot 04)$ were reduced in fish fed the methionine-deficient diet (Fig. 4(a)). Plasma total PL concentrations $(P=0.003)$ were higher in fish fed the methionine-deficient diet when compared with those in fish fed the methionine-supplemented diet (Fig. 4(b)), while plasma bile acid $(P=0 \cdot 28)$, TAG $(P=0.69)$ and cholesterol $(P=0 \cdot 18)$ concentrations were not affected by treatment (Fig. 4(b)). Lipid status in white trunk muscle was not assessed.
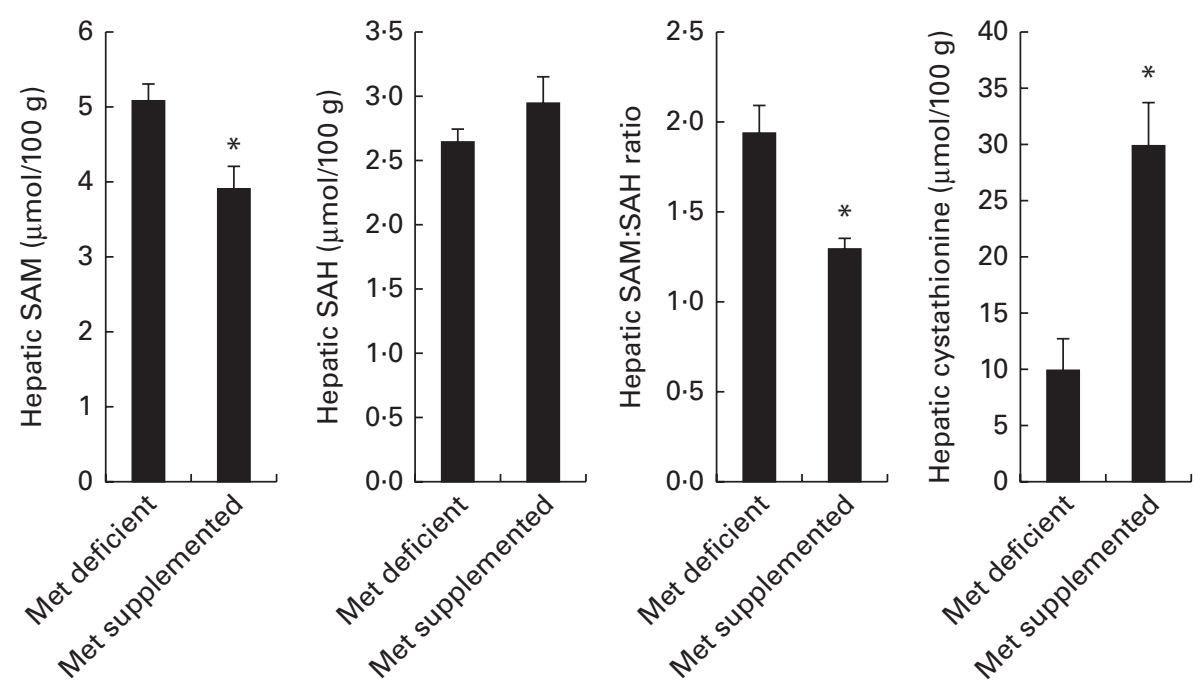

Fig. 2. Concentrations of metabolites involved in hepatic sulphur metabolism of fish fed the methionine (Met)-deficient diet compared with the corresponding values in fish fed the Met-supplemented diet. All values are given in $\mu \mathrm{mol} / 100 \mathrm{~g}$ tissue. Values are means $(n 4)$, with standard errors represented by vertical bars. * Mean value was significantly different from that of fish fed the Met-deficient diet $(P<0.05)$. SAM, $S$-adenosylmethionine; SAH, $S$-adenosylhomocysteine. 

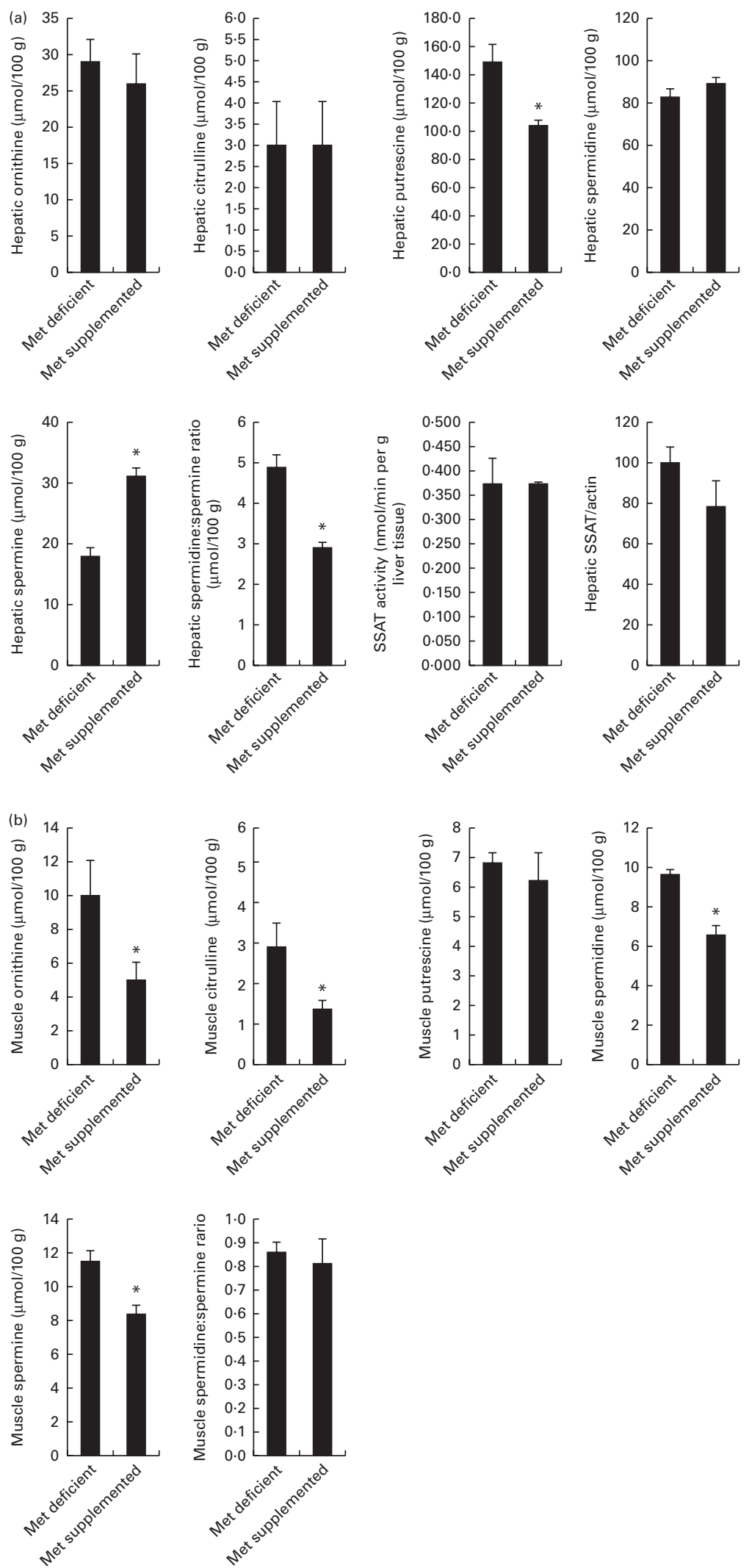

Fig. 3. Polyamine, citrulline and ornithine values in the liver ( $\mathrm{a}, \mu \mathrm{mol} / 100 \mathrm{~g}$ tissue) and white trunk muscle (b, $\mu \mathrm{mol} / 100 \mathrm{~g}$ tissue) of fish fed the methionine (Met)deficient diet compared with the corresponding concentrations in fish fed the Met-supplemented diet. The relative abundances (relative to actin) of spermine/ spermidine acetyltransferase (SSAT) and their activities (CoA-SH produced/min per g liver) are also shown. Values are relative means $(n 4)$, with standard errors represented by vertical bars. * Mean value was significantly different from that of fish fed the Met-deficient diet $(P<0.05)$. 

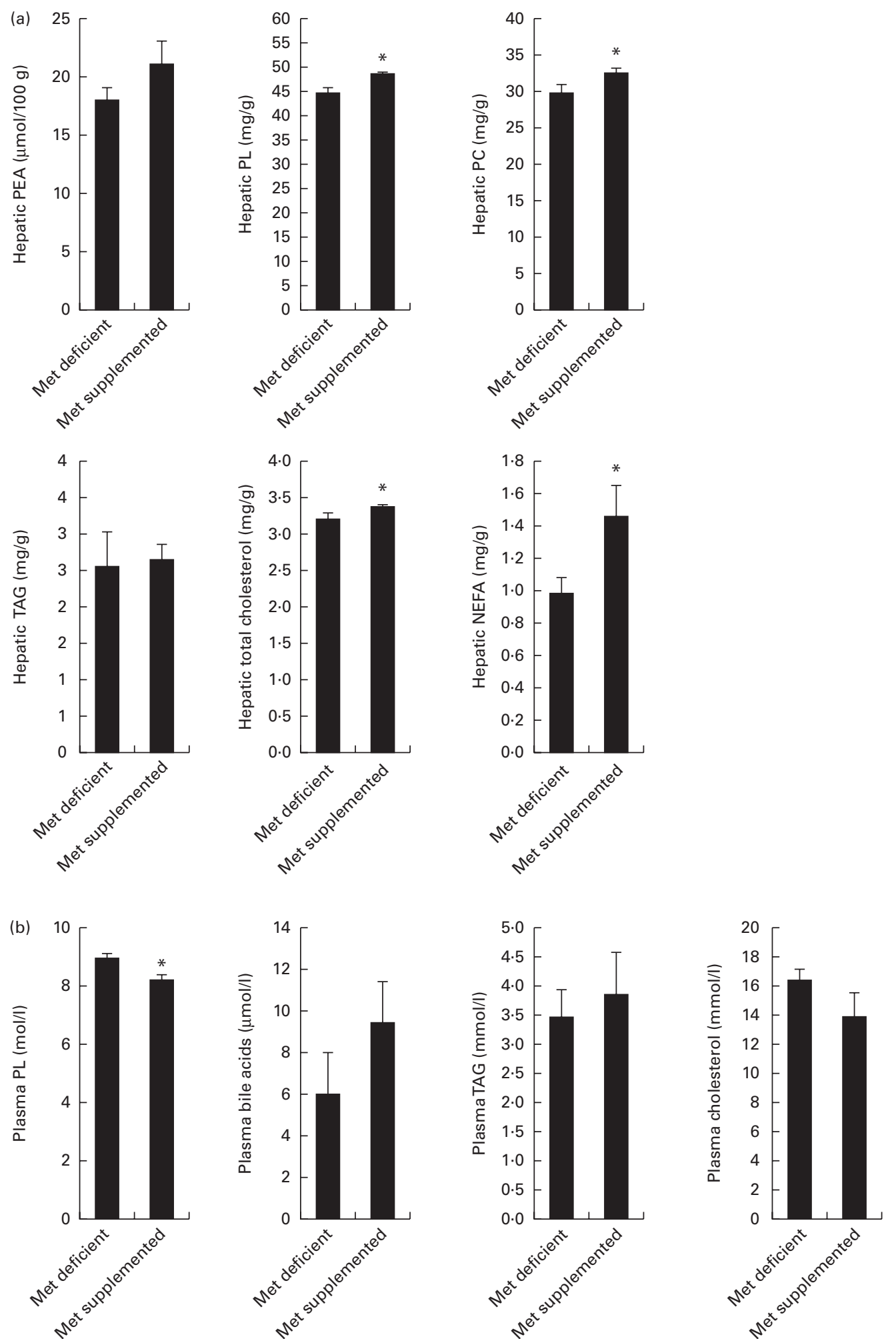

Fig. 4. Phosphatidylethanolamine (PEA, $\mu \mathrm{mol} / 100 \mathrm{~g})$, total phospholipid $(\mathrm{PL}, \mathrm{mg} / \mathrm{g})$, phosphatidylcholine $(\mathrm{PC}, \mathrm{mg} / \mathrm{g})$, TAG $(\mathrm{mg} / \mathrm{g})$, total cholesterol $(\mathrm{mg} / \mathrm{g})$ and NEFA (mg/g) concentrations in the liver (a) of fish fed the methionine (Met)-deficient or Met-supplemented diet. The corresponding concentrations for total PL, TAG and total cholesterol in the plasma are shown (b, mol/l). In addition, plasma total bile acid concentrations are shown ( $\mu$ mol/l). Values are means $(n 4)$, with standard errors represented by vertical bars. ${ }^{*}$ Mean value was significantly different from that of fish fed the Met-deficient diet $(P<0.05)$. 

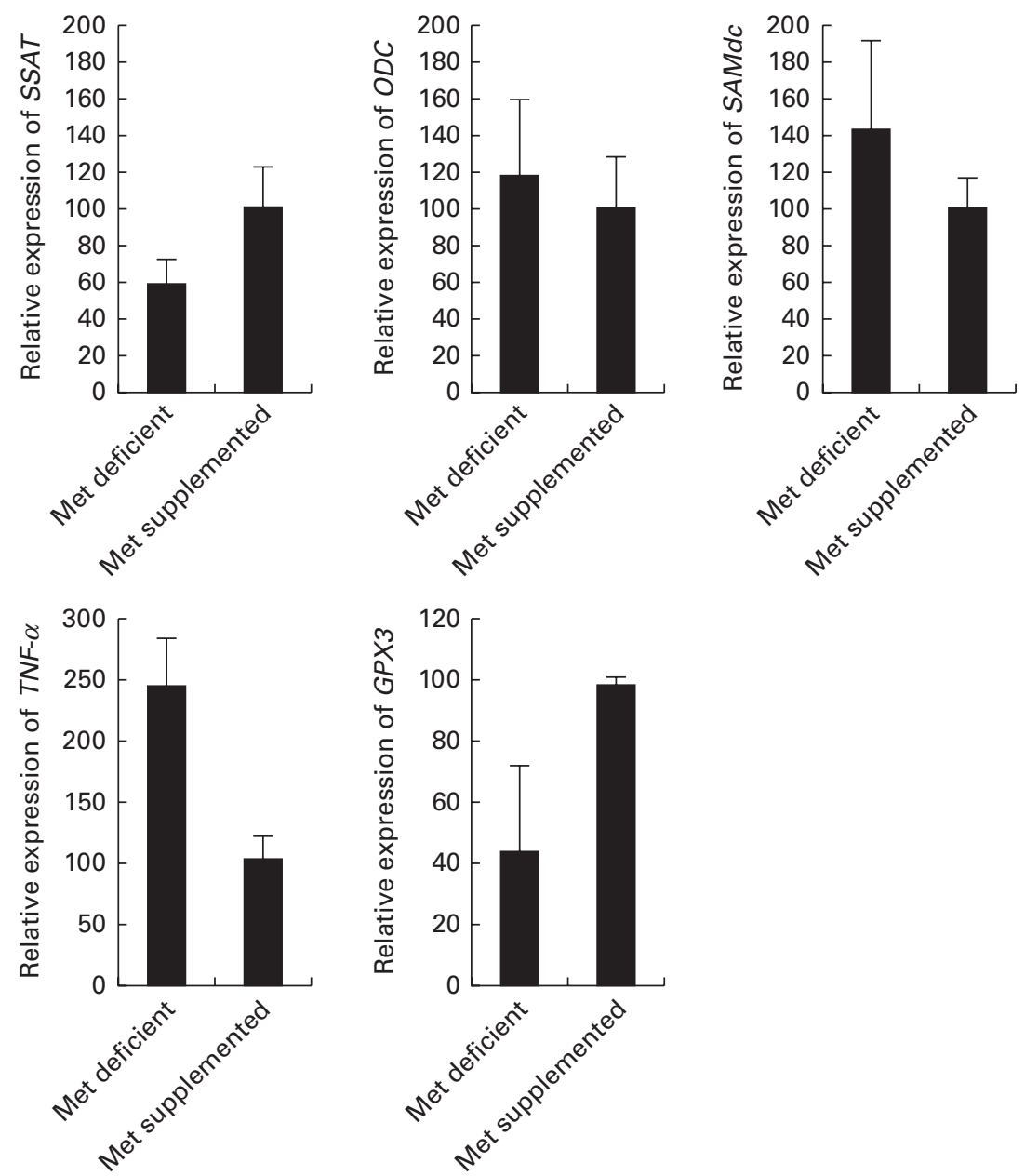

Fig. 5. Normalised gene expression of SAM decarboxylase (SAMdc), ornithine decarboxylase $(O D C)$ and spermine/spermidine acetyltransferase (SSAT) in the liver of fish fed the methionine (Met)-deficient diet compared with that of fish fed the Met-supplemented diet. There was no significant difference between the dietary treatment groups $(P>0.05)$. The expression of TNF- $\alpha$ was higher $(P=0.007)$ and that of glutathione reductase-3 $(G P X 3)$ was lower $(P=0.045)$ in fish fed the Met-deficient diet. Values are presented relative to the expression in fish fed the Met-supplemented diet, the number of which was set to 100 , and values of fish fed the Met-deficient diet were calculated relative to these values. Values are means $(n 4)$, with standard errors represented by vertical bars.

\section{Gene expression in the liver and white adipose tissue}

The gene expression of $S S A T, O D C$ and $S A M d C$ in the liver was not affected by methionine limitation, but that of the cytokine TNF- $\alpha$ was elevated, while that of GPX3 was reduced (Fig. 5). The relative gene expression of Cyp7A1, ApOB10O, CPT-1 and Cat in the liver was not affected by methionine limitation (data not shown). Methionine limitation did not affect the relative gene expression of any of these genes in white adipose tissue (data not shown).

\section{Discussion}

The methionine-deficient diet reduced growth and protein accretion in juvenile Atlantic salmon and concomitantly increased the relative liver weight. However, the higher relative liver weight was not due to TAG accumulation. Previously, we had reported that the increased relative liver weight in Atlantic salmon fed methionine-deficient diets was due to TAG accumulation ${ }^{(2)}$. In that study, the diets were not supplemented with either taurine or choline. Thus, the increased TAG accumulation may be due to choline deficiency rather than due to methionine deficiency. This is in line with results reported by Jacobs et al. ${ }^{(30)}$, who found that choline deficiency rather than methionine deficiency increased TAG accumulation in the liver of rats. Growth suppression and reduced protein accretion were not observed in adult Atlantic salmon fed methionine-choline-deficient diets ${ }^{(1)}$. Therefore, juvenile salmon seem to be less able to handle methionine limitation, and the apparent increased protein catabolism or decreased protein synthesis in muscle tissues results in an increased free lysine concentration in both the muscle and plasma. As muscle was not sampled for real-time quantitative PCR analysis, it is not known whether protein degradation or protein synthesis or both were affected by methionine deficiency. However, these aspects are currently under study.

Surprisingly, SAM concentrations were higher in the liver of fish fed the methionine-deficient diet, while SAH concentrations remained unaffected, resulting in an elevated methylation capacity in the liver of fish with methionine deficiency. Even though taurine is present in the millimolar range in 
most tissues ${ }^{(31,32)}$, including those of fish ${ }^{(1,2)}$, trans-sulphuration has been reported to occur only in the liver, kidney and gastrointestinal tissues of animals ${ }^{(3,4)}$. Rodents fed methionine-deficient diets were found to reduce their trans-sulphuration activity and increase their transmethylation activity, thus keeping free methionine concentrations in the liver within narrow limits ${ }^{(33,34)}$. Fish fed the methionine-deficient diet either reduced their trans-sulphuration activity, as determined from hepatic cystathionine concentrations, or increased the metabolism of cystathionine to taurine and/or glutathione. However, the protein abundance of the rate-limiting enzyme involved in trans-sulphuration, CBS, was not affected by methionine intake as well as taurine and total glutathione concentrations in the liver remained unaltered. Similarly, the transmethylation of homocysteine to methionine, as assessed by BHMT abundance, was not affected. The reduction in plasma and muscle methionine concentrations in fish fed the methionine-deficient diet, keeping hepatic free methionine concentrations constant, is in accordance with results reported from studies carried out previously in Atlantic salmon fed methionine-deficient diets ${ }^{(1,2)}$. The reduction in taurine and free methionine concentrations in the muscle, on the other hand, indicated a redistribution of these metabolites from the muscle to the liver. The increased free lysine and arginine concentrations in muscle may indicate an increased proteolysis or a reduced synthesis of muscle proteins to provide metabolites for liver function and metabolism, as also is supported by the reduced protein accretion in this group. In the present study, muscle samples were not collected for gene expression or protein abundance analysis and so this mechanism cannot be explained. Increased redistribution of choline from the muscle to the liver was found to occur as a result of severe choline deficiency in mice ${ }^{(35)}$. Therefore, muscle samples and possibly other organs should be sampled in the future to enable studies on the redistribution of metabolites between organs in fish when fed diets low in indispensable nutrients.

In addition to acting as a main methyl donor, SAM can function as an aminopropyl donor in polyamine synthesis when decarboxylated ${ }^{(3,9-11)}$. Thus, methionine availability may affect polyamine synthesis. In the present study, methionine limitation indeed affected polyamine concentrations within tissues. However, as neither the gene expression of $S A M d c$ nor that of $O D C$ was affected by treatment and the fact that SAM concentrations were actually elevated in the liver of fish fed the methionine-deficient diet, it is not likely that methionine deficiency reduced the amounts of SAM available for polyamine synthesis. Transgenic mice with increased SSAT activity have been reported to store very low amounts of TAG in the body ${ }^{(12,15)}$. These changes in SSAT activity have been linked to a depletion of futile cycles, ATP and acetylCoA, thus affecting lipid metabolism through increased fatty acid oxidation $^{(12,15,36)}$. Furthermore, these transgenic mice have been found to have reduced cholesterol concentrations due to increased bile acid synthesis ${ }^{(37)}$. In the present study, neither CYP7A1 expression nor cholesterol concentrations indicated an increased cholesterol clearance in fish fed the methionine-deficient diet. Polyamine oxidation occurring through both acetylated polyamine oxidase and polyamine oxidases produces $\mathrm{H}_{2} \mathrm{O}_{2}$, which may increase reactive oxygen species concentrations and affect cell viability ${ }^{(11)}$ However, in the present study, total glutathione concentrations in the liver were not affected by treatment (data not shown). Cells in which both glutathione and polyamines are concomitantly depleted exhibit increased sensitivity to $\mathrm{H}_{2} \mathrm{O}_{2}$ when compared with cells in which only glutathione is depleted $^{(38)}$, implying that glutathione affects reactive oxygen species content by a different mechanism when compared with polyamines. It has been found that taurine supplementation reduces oxidative stress in the heart of Fe-overloaded mice ${ }^{(39)}$ as well as has a prophylactic effect on Cd toxicity in mice ${ }^{(5)}$. Thus, the metabolites involved in sulphur metabolism affect both lipid deposition and cell viability, even though the mechanisms and interactions are still not fully known. Therefore, the activity of polyamine oxidases should also be studied in the future. Methionine itself may be directly oxidised to methionine sulphoxide, which can be regenerated to methionine by the enzyme methionine sulphoxide reductase ${ }^{(40-42)}$. Therefore, the cellular concentrations of methionine, cysteine and taurine may affect the protection of cells against reactive oxygen species. In an in vitro study carried out in primary liver cells isolated from Atlantic salmon, taurine supplementation was found to improve cell viability probably by protecting the mitochondria ${ }^{(8)}$. Mitochondria are the site where the enzymes choline oxidase and choline dehydrogenase, which are necessary for endogenous betaine synthesis from choline, are located ${ }^{(43)}$ As neither BHMT abundance nor hepatic free methionine concentrations were affected by treatment, betaine availability does not seem to have any effect in the liver of juvenile fish. The elevated concentrations of TNF- $\alpha$ may indicate higher inflammation in the liver of the fish fed the methioninedeficient diet, but this does not seem to be due to reduced trans-sulphuration and availability of glutathione or taurine in the liver. Whether this may be linked to polyamine turnover and/or depletion of antioxidative metabolites within other tissue compartments deserves to be studied in more detail.

In the liver, up to $40 \%$ of PC is synthesised through the sequential methylation of phosphatidylethanolamine, and this becomes important when dietary choline content is low $^{(44)}$. De novo synthesis of choline from phosphatidylethanolamine requires three successive methyl groups from SAM through the enzyme PEMT. Choline deficiency was found to lead to increased oxidative stress in the liver of mice in addition to TAG accumulation ${ }^{(45)}$. It is known that rats fed diets deficient in choline exhibit increased hepatic TAG and 1,2-diacylglycerol accumulation ${ }^{(46)}$. Previously, we had reported TAG accumulation to occur in the liver of salmon fed methionine-choline-deficient $\operatorname{diets}^{(2)}$. In the present study, no TAG accumulation was found to occur due to methionine deficiency, but an unidentified peak was found in the chromatograms immediately following the TAG peak, but this was not the 1,2-diacylglycerol peak. Phosphatidylcholine concentrations were reduced in the liver of fish fed the methionine-deficient diet, which indicates a reduced de novo synthesis of PC and/or a different distribution between 
body compartments. As PEMT abundance was not affected by methionine limitation, it is likely that the de novo synthesis of choline was not altered in the present study, as gene expression and thus protein abundance of PEMT have been reported to increase as a result of choline deficiency in rats $^{(47)}$. Due to shortage of materials, neither the activity of PEMT nor its gene expression could be analysed, but these should be analysed in future studies to determine whether PEMT is affected by methionine limitation. However, total PL concentrations, and especially PC concentrations, were reduced in the liver of fish fed the methionine-deficient diet. In a previous study, no significant decrease in PL concentrations in the liver of adult Atlantic salmon fed methioninecholine-deficient diets was found, while TAG accumulation was found to occur ${ }^{(2)}$. The development of fatty liver thus seems to be more due to choline-methionine deficiency rather than due to methionine deficiency. Therefore, the interactions between choline deliveries at different methionine intake levels and at different fish sizes should be studied in more detail to understand their metabolic interactions and signalling resulting in a different growth pattern and their possible effects on fish health.

\section{Conclusion}

Methionine limitation reduced growth and protein accretion in juvenile Atlantic salmon, but did not deplete hepatic SAM. Polyamine turnover, as assessed by SSAT activity and abundance, was not affected by methionine deficiency. However, polyamine concentrations were affected, which may be due to the increased free lysine and arginine concentrations as a result of methionine deficiency. No TAG accumulation was detected in the liver as a result of methionine deficiency when diets were supplemented with choline, but methionine deficiency reduced hepatic PL concentrations and increased plasma PL concentrations. Methionine deficiency seemed to increase muscle proteolysis and/or decrease protein synthesis as well as deplete the antioxidants in muscle as taurine. Based on these findings, future trials should include several compartments to increase the knowledge of nutrient limitation and distribution of metabolites between organs and their effects on metabolism and health to fully understand the consequences of nutrient limitation on health.

\section{Acknowledgements}

The authors thank Jannicke Vigen from the EWOS Innovation AS for taking care of the experimental fish. They also cordially thank Anita Birkenes and Synnøve Wintertun from the National Institute of Nutrition and Seafood Research for their technical support.

The present study was supported by the project Integrated Amino Acid Requirement financed by The Norwegian Research Council (project no. 208352/E-40) and EWOS Innovation AS.

The authors' contributions are as follows: A. A., J.-E. Z. and M. E. designed the experiment; A. A. conducted the experiment; M. E. wrote the manuscript. All authors collected the samples and analysed them and contributed to and approved the final manuscript.

None of the authors has any conflicts of interest to declare.

\section{References}

1. Espe M, Hevrøy EM, Liaset B, et al. (2008) Methionine intake affect hepatic sulphur metabolism in Atlantic salmon, Salmo salar. Aquaculture 274, 132-141.

2. Espe M, Rathore RM, Due Z-Y, et al. (2010) Methionine limitation results in increased hepatic FAS activity, higher liver 18:1 to 18:0 fatty acid ratio and hepatic TAG accumulation in Atlantic salmon, Salmo salar. Amino Acids 39, 449-460.

3. Mato JM, Corrales FJ, Lu SC, et al. (2002) S-Adenosylmethionine: a control switch that regulates liver function. FASEB $J$ 16, 15-26.

4. Finkelstein JD (2006) Inborn errors of sulfur-containing amino acid metabolism. J Nutr 136, 1750S-1754S.

5. Sinha M, Manna P \& Sil PC (2009) Induction of necrosis in cadmium-induced hepatic oxidative stress and its prevention by the prophylactic properties of taurine. I Trace Elem Med Biol 23, 300-313.

6. Ozden D, Catalgol B, Gezginci-Oktayoglu S, et al. (2009) Methiocarb-induced oxidative damage following subacute exposure and the protective effects of vitamin $\mathrm{E}$ and taurine in rats. Food Chem Toxicol 47, 1676-1684.

7. Devi SL \& Anuradha CV (2010) Mitochondrial damage, cytotoxicity and apoptosis in iron-potentiated alcoholic liver fibrosis: amelioration by taurine. Amino Acids 38, 869-879.

8. Espe M \& Holen E (2013) Taurine attenuates apoptosis in primary liver cells isolated from Atlantic salmon. $\mathrm{Br} J$ Nutr 110, 20-28.

9. Nisenberg O, Pegg AE, Welsh PA, et al. (2006) Overproduction of cardiac $S$-adenosylmethionine decarboxylase in transgenic mice. Biochem J 393, 295-302.

10. Pegg AE (2009) Mammalian polyamine metabolism and function. IUBMB Life 61, 880-894.

11. Casero RA \& Pegg AE (2009) Polyamine catabolism and disease. Biochem J 421, 323-338.

12. Pirinen E, Kuulasmaa T, Pietilä M, et al. (2007) Enhanced polyamine catabolism alters homeostatic control of white adipose tissue mass, energy expenditure, and glucose metabolism. Mol Cell Biol 27, 4953-4967.

13. Espe M, Ruohonen K \& El-Mowafi A (2012) Effect of taurine supplementation on the metabolism and body lipidto-protein ratio in juvenile Atlantic salmon (Salmo salar). Aquacult Res 43, 349-360.

14. Espe M, Ruohonen K \& El-Mowafi A (2012) Hydrolysed fish protein concentrate (FPC) reduces viscera mass in Atlantic salmon (Salmo salar) fed plant-protein-based diets. Aquacult Nutr 18, 599-609.

15. Jell J, Merali S, Hensen ML, et al. (2007) Genetically altered expression of spermidine/spermine $N^{1}$-acetyltransferase affects fat metabolism in mice via acetyl-CoA. J Biol Chem 282, 8404-8413.

16. NRC (2011) National Research Council, Nutrient Requirements of Fish and Shrimp, Committee on the Nutrient Requirements of Fish and Shrimp. Washington, DC: The National Academies Press.

17. Espe M, Lemme A, Petri A, et al. (2006) Can Atlantic salmon (Salmo salar) grow on diets devoid of fish meal? Aquaculture 255, 255-262.

18. Wang W, Kramer M, Yang S, et al. (2001) Reversed-phase high-performance liquid chromatography procedure for the simultaneous determination of $S$-adenosyl-L-methionine 
and $S$-adenosyl-L-homocysteine in mouse liver and the effect of methionine on their concentration. J Chromatogr $B$ Biomed Sci Appl 762, 59-65.

19. Bell JG, Dick JR, McVicar AH, et al. (1993) Dietary sunflower, linseed and fish oils affect phospholipid fatty acid composition, development of cardiac lesions, phospholipase activity and eicosanoid production in Atlantic salmon (Salmo salar). Prostaglandins Leukot Essent Fatty Acids 49, 665-673.

20. Liaset B, Julshamn K \& Espe M (2003) Chemical composition and theoretical nutritional evaluation of the produced fractions from enzymatic hydrolysis of salmon frames with Protamex $^{\mathrm{TM}}$. Proc Biochem 38, 1747-1759.

21. Liaset B \& Espe M (2008) Nutritional composition of soluble and insoluble fractions obtained by enzymatic hydrolysis of fish-raw materials. Process Biochem 43, 42-48.

22. Lin HJ, Lien YC \& Hsu CH (2010) A high-throughput colorimetric assay to characterize the enzyme kinetic and cellular activity of spermidine/spermine $N^{1}$-acetyltransferase 1 . Anal Biochem 407, 226-232.

23. Torstensen BE, Espe M, Stubhaug I, et al. (2011) Dietary plant proteins and vegetable oil blends increase adiposity and plasma lipids in Atlantic salmon (Salmo salar L.). Br J Nutr 106, 633-647.

24. Andersen SM, Holen E, Aksnes A, et al. (2013) Dietary arginine affects energy metabolism through polyamine turnover in juvenile Atlantic salmon (Salmo salar). Br J Nutr 110, 1968-1977.

25. Kennedy SR, Leaver M, Campbell PJ, et al. (2006) Influence of dietary oil content and conjugated linoleic acid (CLA) on lipid metabolism enzyme activities and gene expression in tissues of Atlantic salmon (Salmo salar). Lipids $\mathbf{4 1}$, 423-436.

26. Chuang W-L, Haugland $\varnothing$, Pan BS, et al. (2008) Isoflavonerich extracts from wooly glycine Glycine tomentella inhibits LPS-induced TNF- $\alpha$ expression in a macrophage cell line of Atlantic salmon (Salmo salar L.). Molecul Immunol $\mathbf{4 5}$, 3956-3964.

27. Liland NS, Espe M, Rosenlund G, et al. (2013) High levels of dietary phytosterols affect lipid metabolism and increase liver and plasma TAG in Atlantic salmon (Salmo salar L.). Br J Nutr 110, 1958-1967.

28. Todocevi M, Skugor S \& Ruyter B (2010) Alterations in oxidative stress status modulate terminal differentiation in Atlantic salmon adipocytes cultivated in media rich in $n-3$ fatty acids. Comp Biochem Physiol B Biochem Mol Biol 156, 309-318.

29. Olsvik P, Lie K, Jordal A-E, et al. (2005) Evaluation of potential reference genes in real-time RT-PCR studies of Atlantic salmon. BMC Mol Biol 6, 21-29.

30. Jacobs RL, Zhao Y, Koonen DPY, et al. (2010) Impaired de novo choline synthesis explains why phosphatidylethanolamine $N$-methyltransferase-deficient mice are protected from diet-induced obesity. J Biol Chem 285, 22403-22413.
31. Schuller-Levis GB \& Park E (2003) Taurine: new implications for an old amino acid. FEMS Microbiol Letters 226, 195-222.

32. Bouckenooghe T \& Reusens B (2006) Is taurine a functional nutrient? Curr Opin Clin Nutr Metab Care 9, 728-733.

33. Park E, Garrow L, Renduchintala M, et al. (1997) Methionine deficiency increases betaine-homocysteine methyltransferase (BHMT) activity and mRNA levels in rat liver. FASEB $J$ 11, 2121-2121.

34. Strakova J, Guptka S, Kruger WD, et al. (2011) Inhibition of betaine-homocysteine $S$-methyltransferase in rats causes hyperhomocysteinemia and reduces liver cystathionine $\beta$-synthase activity and methylation capacity. Nutr Res 31, 563-571.

35. Li Z, Agellon LB \& Vance DE (2007) Choline redistribution during adaptation to choline deprivation. J Biol Chem 282, 10283-10289.

36. Pegg AE (2008) Spermidine/spermine- $N(1)$-acetyltransferase: a key metabolic regulator. Am J Physiol Endocrinol Metab 294, E995-E1010.

37. Pirinen E, Gylling H, Itkonen P, et al. (2010) Activated polyamine catabolism leads to low cholesterol levels by enhancing bile acid synthesis. Amino Acids 38, 549-560.

38. Rider JE, Hacker A, Mackintosh CA, et al. (2007) Spermine and spermidine mediate protection against oxidative damage caused by hydrogen peroxide. Amino Acids $\mathbf{3 3}$, $231-240$

39. Oudit GY, Trivieri MG, Khaper N, et al. (2004) Taurine supplementation reduces oxidative stress and improves cardiovascular function in an iron-overload murine model. Circulation 109, 1877-1885.

40. Stadtman ER, Van Remmen H, Richardson A, et al. (2005) Methionine oxidation and aging. Biochim Biophys Acta 1703, 135-140.

41. Oien B \& Moskovitz J (2009) Selenium and the methionine sulfoxide reductase system. Molecules 14, 2337-2344.

42. Brennan L \& Kantorow M (2009) Mitochondrial function and redox control in the aging eye: role of MsrA and other repair systems in cataract and macular degenerations. Experim Eye Res 88, 195-203.

43. Obeid R \& Herrmann W (2009) Minireview: Homocysteine and lipids: $S$-adenosyl methionine as a key intermediate. FEBS Letters 583, 1215-1225.

44. Vance DE \& Ridgeway ND (1988) The methylation of phosphatidylethanolamine. Prog Lipid Res 27, 61-79.

45. Yoshida Y, Itoh N, Hayakawa M, et al. (2006) Lipid peroxidation in mice fed a choline-deficient diet as evaluated by total hydroxyoctadecadienoic acid. Nutrition 22, 303-311.

46. Zeisel SH, da Costa KA, Albright CD, et al. (1995) Choline and hepatocarcinogenesis in the rat. Adv Exp Med Biol 375, 65-79.

47. Cui Z \& Vance DE (1996) Expression of phosphatidylethanolamine $N$-methyltransferase-2 is markedly enhanced in long term choline-deficient rats. J Biol Chem 271, 2839-2843. 